\title{
Biochemical and Instrumental Characterization of Vermicompost Produced From Patchouli Bagasse: A Waste by-product of Essential Oil Industries
}

\section{Refad Ahmed}

Gauhati University

Hemen Deka ( $\nabla$ hemendeka@gauhati.ac.in )

Gauhati University

\section{Research Article}

Keywords: Patchouli bagasse, Vermicompost maturity, XRD, SEM, Dehydrogenase, Urease

Posted Date: August 23rd, 2021

DOl: https://doi.org/10.21203/rs.3.rs-807431/v1

License: (c) (1) This work is licensed under a Creative Commons Attribution 4.0 International License.

Read Full License 


\section{Abstract}

Biochemical and instrumental analysis was carried out for understanding the maturity and stability of the vermicomposted patchouli bagasse (PB) and cow dung (CD) mixtures. Two important enzymes namely urease and dehydrogenase were evaluated to understand the biological changes. On the other hand, instrumental study includes scanning electron microscopy (SEM) imaging; X-ray diffraction (XRD) pattern and UV-VIS spectrophotometer analysis of the vermicomposting end products. The results showed enhancement in urease (1.14-2.84 folds) and dehydrogenase (1.7-3.1 folds) activities confirming the maturity and stability of the vermicomposting end products. The spectrophotometric analysis revealed that there was significant decrease in humification index ( 1.5 to 3.4 folds) in the vermicompost samples than the initial level. The SEM images depicted the porous, fragmented and granular structure of end vermicompost samples. Further, the XRD analysis showed the micromorphological crystalline structure and enhanced decomposition of the substrate mixture during vermicomposting process. As a whole, the end vermicompost product was found to be much stable and mature for agronomic use.

\section{Introduction}

Vermicomposting is an eco-biotechnological process for management of waste of organic origin. During vermicomposting, combined action of earthworms and microbes accelerate the waste/substrate decomposition process and thus stabilizes the raw waste and convert it into value-added products (Patwa et al. 2020). Vermicomposting of biowaste has gain a research attention globally and reflected as auspicious and justifiable bio based technology to recycle organic waste (Srivastava et al. 2020). Several studies have already established the suitability of vermitechnology in mitigation of organic waste (Yuvaraj et al. 2019; Pellejero et al. 2020) including the waste bagasse of aromatic plants industries (Boruah et al. 2019). Nonetheless, understanding of stability and maturity of vermicomposting products are utmost important as these are linked with the harvest efficacy and agricultural applicability.

The physico-chemical parameters such as $\mathrm{pH}$, conductivity, macronutrients, micronutrients, $\mathrm{C} / \mathrm{N}, \mathrm{C} / \mathrm{P}$ and ash profiling are being used as reliable indicators to understand the nutrient dynamics, decomposition pattern and organic biomass stabilization during vermicomposting process (Pellejero et al. 2020; Boruah and Deka 2021). However, apart from these, biochemical and instrumental evaluations are also necessary for deeper understanding of stability/maturity of the vermicomposting end products. The primary goal of any vermicomposting operation is to deliver suitable end products that are safe for agronomic use or land applications (Sudkolai and Nourbakhsh 2017). Therefore, proper evaluation of stability/maturity of vermicomposted products employing reliable indicators are utmost important. In this context, both biochemical and instrumental characterization of final vermicomposting products are necessary.

Several studies have highlighted the use and importance of biochemical and instrumental assays for understanding compost maturity/stability (Lim and Wu 2015; Bhat et al. 2017; Boruah and Deka 2021). Biological indicators such as assessment of enzymatic activities and humification index has been found 
to be unfailing parameters for evaluation the vermicompost stability (Boruah and Deka 2021). Enzyme activities implies the growth of microorganism, its metabolism (Romero et al. 2010; Cai et al. 2020) and ensures the degree of waste degradation by microbial release during the vermicomposting process (Boruah and Deka 2021). For example, urease and dehydrogenase activities are measured to assess the impact of microbial community and role of urea during the vermicomposting process (Yadav et al. 2015; Pellejero et al. 2020; Srivastava et al. 2020). Similarly, the humification index is found to be reliable and well used parameters to study the vermicompost stability (Das and Deka 2021). Upon the decomposition of substrate the humification index gets reduced and gives the idea regarding degree of degradation, oxidation and decomposition (Lim et al. 2015b; Ganguly and Chakraborty 2019) of the vermicomposting substrates. Further, the instrumental analyses such as scanning electron microscopic (SEM) and x-ray diffraction (XRD) are frequently used to evaluate the quality of the vermicomposted products. A complete micro-morphological changes and the degradation pattern of the vermicomposting substrate can be obtained through SEM analysis (Bhat et al. 2018). Similarly, XRD analysis provides deeper understanding in cellulose biodegradation and crystalline microstructure changes in the vermicomposted substrates (Lim et al., 2015; Bhat et al., 2018).

Patchouli bagasse is the by-product, generated during essential oil production from the aromatic herb patchouli (Pogostemon cablin) in different agro-based industries around the globe. In context of aromatic plant biomass production, India's annual contribution is more than six million tons to the total global outlet of 20,000 million tonnes (Boruah and Deka 2021) and these huge biomass are usually dumped unscientifically in the open spaces. Considering the environmental impact of waste dumping sites (Powell et al. 2016), vermicomposting potential of patchouli bagasse as well as agronomic potential of the end products were studied by few earlier workers (Singh et al. 2013). However, biochemical parameters such as enzyme assay, humification process and instrumental analysis for proper understanding of stability/maturity of the vermicomposting end products were not studied during any earlier study. Thus, the present study has been designed to cover the knowledge gap of previous works. In this study, role of urease, dehydrogenase and humification index in stabilization of vermicomposted end products of patchouli bagasse and cowdung mixture was investigated. Besides, efficacy of vermicomposting process was also determined by SEM and XRD evaluations.

\section{Materials And Methods}

\subsection{Collection of patchouli bagasse (PB), cow dung (CD) and earthworms}

The PB was collected from the Brahmaputra Valley Aromatic Oil Industry, Kaliabor Tiniali, Assam, India. The collected PB was air dried and cut into small pieces for experimental use. Urine free fresh CD was locally collected from a household livestock of the Gauhati University campus. The experimental earthworm Eisenia fetida was collected from the vermicomposting research unit of Central Plantation Crops Research Institute, Kahikuchi, Assam, India. For future use, a stock culture of the collected 
earthworms was maintained in the vermicomposting unit placed at the Dr. H.K. Boruah Regional Botanical Resource Centre, Gauhati University, Guwahati, Assam, India.

\subsection{Experimental setup}

The vermicomposting experiment was carried out in plastic pots of $500 \mathrm{ml}$ capacity taking the different combinations of patchouli bagasse (PB) and cowdung (CD) mixture as the substrates. The different treatments combination were T1 (5:0), T2 (5:1), T3 (5:2), T4 (5:3), T5 (5:4), T6 (5:5), T7 (4:5), T8 (3:5), T9 (2:5), T10 (1:5), T11 (0:5) with the proper mixing of PB and CD. A similar setup was also maintained without earthworms as control (traditional composting). Each treatment was done in triplicates for statistical assessments. The experimental pots were covered with newspaper and small holes were created for proper aeration. Temperature and moisture content of the pots were maintained by sprinkle of water with a definite interval of time (Yuvaraj et al. 2019). The substrate mixture of each treatment was pre-decomposed for 15 days in order to make them palatable for the earthworms (Karmegam et al. 2019; Pellejero et al. 2020). A total of 15 individuals of Eisenia fetida were introduced in the experimental pots. At the end of 50 days of vermicomposting period the harvesting was done and further analysis were carried out.

\subsection{Measuring the dehydrogenase and urease activities}

For evaluation of dehydrogenase activities of the samples method of Garcia et al. (1997) with slight modifications. To analyse the dehydrogenase activity, $0.5 \mathrm{~g}$ of sample was incubated at $25^{\circ} \mathrm{C}$ for 24 hours with $0.2 \mathrm{~mL}$ of $0.4 \%$ 2-piodophenyl-3 p-nitrophenyl-5 tetrazolium chloride (INT) as a substrate. Production of Iodonitrotetrazoliumformazan (INTF) as a result of lessening of INT was extracted by employing a mixture of acetone: tetrachloroethene (3:2) and quantified spectrophotometrically at $250 \mathrm{~nm}$ and outcomes were expressed as $\mu \mathrm{g}$ INTF g-1 h-1. Assays without INT were used as a control treatment for this test.

The method suggested by Hoffmann and Teicher (1961) was used for the quantification of urease activities of the samples. For the purpose, $0.25 \mathrm{ml}$ toluene, $0.75 \mathrm{ml}$ citrate buffer $(\mathrm{pH} 6.7)$ and $1 \mathrm{ml}$ of $10 \%$ urea substrate solution were added to the $1 \mathrm{~g}$ sample and incubated for $3 \mathrm{~h}$ at $37^{0} \mathrm{C}$. The formation of ammonium was determined spectrophotometrically at $578 \mathrm{~nm}$ and results were expressed as $\mu \mathrm{g} \mathrm{NH}{ }_{4}^{+} \mathrm{g}^{-}$ ${ }^{1} \mathrm{~h}^{-1}$ dry sample. A control sample without adding any urea to each samples were also analysed for comparison of the results.

\subsection{Spectrophotometric analysis for humification index}

Concentration of organic material in a substance is expressed as humification index (HI). It signifies the integration and disintegration of vermicompost material. It was determined by using the method as outlined by Zbytniewski and Buszewski (2005). Briefly, $1 \mathrm{~g}$ of sample of vermicompost was thoroughly shacked after mixing with $50 \mathrm{ml}$ of $0.5 \mathrm{M} \mathrm{NaOH}$, left for overnight and centrifuged (REMI R-8C Laboratory Centrifuge) at $3000 \mathrm{rpm}$ for $25 \mathrm{~min}$. Then the supernatants were taken for measuring the absorbance 
through spectrophotometer (Systronics UV-VIS Spectrophotometer 119) at wavelength of $472 \mathrm{~nm}\left(\mathrm{~A}_{472}\right)$ and $664 \mathrm{~nm}\left(\mathrm{~A}_{664}\right)$ and the ratio obtained was expressed as $\mathrm{HI}$.

\subsection{Scanning Electron Microscopy (SEM)}

All the samples were oven dried properly and the moisture contents were removed for SEM analysis. For SEM imagery analysis, samples from all the treatments were mixed separately for initial substrate, compost and vermicompost materials respectively. By using double-sided adhesive carbon tape the samples were fixed on a metallic sample holder and coated with gold through sputter coater for clear visibility of picture (Bhat et al. 2015). Micrographs of surface morphology of the samples were recorded at different magnifications of scanning electron microscopy (Gemini, Sigma-300 series).

\subsection{X- ray diffraction (XRD) analysis}

X- ray diffraction (XRD) patterns of initial substrate, compost and vermicompost samples were obtained using a Powder X-ray Diffractometer (PXRD-EMPYREAN). Fine powdered form of $3 \mathrm{~g}$ of sample was placed on glass slide of size $2 \mathrm{~cm} \times 3.5 \mathrm{~cm}$ and thickness $0.2 \mathrm{~cm}$ with uniform layer of size $2 \mathrm{~cm} \times 1.5 \mathrm{~cm}$ on one side. The output consists of $X$-ray diffractogram, peak position, $d$ values and relative intensity data. The phase identification, quantitative analysis of minerals, grazing incidence XRD of thin film, determination of unit cell parameters, particle size measurement $(\lambda=0.154 \mathrm{~nm})$ was operated at $40 \mathrm{kV}$ and $40 \mathrm{~mA}$. Samples were scanned over the range of $2 \theta=5-40^{\circ}$ with a step interval of $0.01^{\circ}($ Wang et al. 2019).

\subsection{Statistical Analysis}

All the experimental data were expressed as mean \pm standard deviation of three replicates. ANOVA, LSD test $(P<0.01)$ was used to compare the differences in urease, dehydrogenase and humification index values of substrate, compost and vermicompost samples.

\section{Results}

\subsection{Humification Index (HI)}

The results of $\mathrm{HI}$ index of various samples of substrate mixture, compost and vermicompost are graphically presented in the Fig. 1. The results showed significant decrease in HI values in the vermicompost samples when compared with the traditional compost and initial substrate mixture. The average value of $\mathrm{HI}$ was recorded as $7.19 \pm 0.33$ in the initial feed mixture. The $\mathrm{HI}$ value was found within the range of $2.82 \pm 0.09$ to $5.06 \pm 0.13$ in compost and $2.10 \pm 0.03$ to $4.71 \pm 0.11$ in the vermicompost samples. Thus, the reduction in $\mathrm{HI}$ level was found to be 1.4 to 2.6 folds in compost and 1.5 to 3.4 folds in the vermicompost samples.

\subsection{Quantification of dehydrogenase and urease}


Enzyme quantification is an important aspect in understanding vermicompost stability and maturity. The dehydrogenase (DH) and urease (UR) profiles in the samples of substrate material, compost and vermicompost are shown in Fig. 2 and Fig. 3 respectively. The results as revealed in Fig. 2, showed significant rise in the $\mathrm{DH}$ activities for both compost and vermicompost samples when compared with initial level of substrate mixtures. The DH values were found higher in the vermicompost samples of all the treatments than the compost counterparts. Thus, the enhancement in $\mathrm{DH}$ level was recorded in the range of 1.1-2.1 folds in compost and 1.7-3.1 folds in the vermicompost samples. Similarly, there was increase in the UR activities in both compost and vermicompost samples over the initial substrate. The UR values were found higher in the vermicompost samples of all the treatments except the T3, T6, T7 and T11. As a whole, the raise in the UR activities were found to be in the range of 1.14-2.84 folds in the vermicompost samples and 1.09-2.2 folds in case of compost samples over the initial substrate mixture.

\subsection{Scanning Electron Microscopy Evaluation}

The SEM snapshots showed the variations in micromorphological structure of the samples of initial substrate, compost and vermicompost (Fig. 4). The SEM image of initial substrate mixture reveals compact and unbroken structures without any pores and fragmentation. On the other hand, the stabilization as well as degradation of the waste mixers was evident in the vermicompost and compost samples. The vermicompost samples showed more porous, fragmented and granular structures which were significantly less in case of compost/control. Further, SEM micrographs of raw clearly showed that surface area of vermicompost samples are higher when compared with those of traditional compost and initial substrate mixture.

\subsection{X- ray diffraction (XRD) Analysis}

The XRD graph peak intensities of the studied samples have been interpreted based on the previous references (Wang et al. 2019; Chen et al. 2020). The x-ray diffraction intensity of the initial substrate mixture, compost and vermicompost samples showed variations in peak intensities (Fig. 5). The peak intensity of cellulose was decreased from raw material to vermicompost. From the diffraction intensity it was revealed that the degree of polymerisation of the initial substrate mixture was reduced and enhanced decomposition has occurred. For all the samples the crystalline region for cellulose were traced near $2 \theta=$ $22^{\circ}$. Besides, a strong peak near the $2 \theta=26.6^{\circ}$ indicating diffraction peak of $\mathrm{SiO}_{2}$ was evident in all the samples.

\section{Discussion}

Humification index is an indicative parameter for compost/vermicompost stabilization (Das and Deka 2021). The decreasing trend in $\mathrm{HI}$ level after vermicomposting process has already been reported by earlier workers (Negi and Suthar 2018; Boruah et al. 2019). The reductions in the HI value infer the gradual breakdown and deprivation of organic complexes in the substrate mixture due to joint action of available microbes and the earthworm. It has been suggested that the lower values of $\mathrm{HI}$ in vermicomposted materials strongly supports the active action of earthworm and microbes during the 
organic waste degradation (Boruah et al. 2019). Besides, the low HI value directly correlates with the high level of humification of organic material (Bhat et al. 2017) during the vermicomposting process. The high degree of humification, oxidation, degradation and decomposition of organic material indicates the smaller value of $A_{472} / A_{664}$ which implies about the maturity and stability of the vermicompost product against initial substrate mixture (Ganguly and Chakraborty 2019). The lower HI value (less than 5 ) in the vermicompost samples in the present study indicates high level of organic matter humification and stabilization of the end product (Hussain et al. 2016) and confers the suitability for agronomic use.

The elevation in both dehydrogenase and urease activities in the vermicompost samples are in conformity with the previous findings (Pramanik et al. 2007; Yadav et al. 2015; Boruah and Deka 2021). The rise in enzyme activities could be related to the enhanced level of nutrients in the vermicomposting end products. It has been suggested that active participation of microbes and earthworms in the vermicomposting systems accelerates rapid mineralization of the substrate mixtures and enhanced the nutrients level in the end vermicompost samples (Senthil Kumar et al. 2014). Besides, the increased in dehydrogenase enzyme activities from raw material mixture to vermicompost might be due to availability of feed mixture for the growth of microbes and hence better degradation of the raw materials resulting in rapid enzyme production (Pandit et al. 2020). Dehydrogenase activities are a reliable indicator to understand the waste degradation and maturity of the vermicomposting end products. Dehydrogenase assay tells about the microbial activity of the samples as because its occurrence in the intracellularly in all the microbial cells and can be a good sign of microbial biomass (Usmani et al. 2019; Boruah and Deka 2021). Urease catalyzes the transformation urea present in the samples into carbon dioxide and ammonia. As urease is involve in hydrolysis of proteinaceous substance into ammonia for which the nitrogen content in the substrate increases resulting in a significantly more mature vermicompost product at the end of trial (Haritha Devi et al. 2009; Boruah and Deka 2021).Both increase and decrease in urease activities is possible during vermicomposting and this could be related with the initial substrate combinations and micro-environmental conditions therein (Pramanik et al. 2007). Besides, increase in urease activities in the vermicompost samples are associated with the initial $\mathrm{NH}_{4}$ level in the feed materials, enhanced decomposition and mineralization of substrate due to joint activities of earthworms and microbes (Wang et al. 2021).Whereas, decline in urease level during vermicomposting is related with the less biodegradable compounds in the end vermicompost samples(Wang et al. 2021). As a whole, diverse substrate conditions due to different ratios of cow dung cause micro-environmental differences thereby resulting increase as well as decrease in urease activities in the final vermicompost.

Several researchers have performed SEM evaluation for understanding the changes in surface morphology of pre- and post-vermicomposted substrate/substrate mixtures and maturity of the end vermicompost samples(Senthil Kumar et al. 2014; Unuofin and Mnkeni 2014; Sharma and Garg 2018; Srivastava et al. 2020). The nonporous and compact structure as revealed in the SEM image of substrate materials could be related with cellulose and protein groups that are tightly bound with the lignin as an assortment(Senthil Kumar et al. 2014).During vermicomposting the protein and lignin matrix is disaggregated due to joint action of earthworms and microbes which is reflected as the porous and 
fragmented structures (Hussain et al. 2016) in the SEM micrographs. It has been suggested that earthworms ingest and grind the substrate in their gizzard and passed it to the intestine where enzymes and microbes carry out further degradation and disaggregation (Bhat et al. 2017)before released as excreta. Besides, numerous surface irregularities due to joint action of earthworms and microbes confirms the maturity of the final vermicompost (Ravindran et al. 2008)and suitable for agricultural applications. Finally, the irregular surface morphology with large numbers of pores in the SEM micrographs of vermicompost samples can also be related with the high CEC values due to high humification of the substrate materials during vermicomposting(Senthil Kumar et al. 2014; Lim et al. 2015a).

XRD analysis helps in understanding the cellulose degradation pattern of the substrate materials during vermicomposting and provides an idea about micromorphological changes in crystalline structure of the substrate materials. The cellulose is the main composition of the plant cell wall and is hard to break through conventional composting in shorter time. Digestion by microorganism followed by active action earthworms cause destruction of macromolecular chain rapidly which leads to displacement of separate structural element (Chen et al. 2010).Vermicomposting significantly increased the peak intensity at $26.6^{\circ}$ which is supposed to be due to degradation of organic matter and increase in humic substance as well as ash content(Chen et al. 2010; Arumugam et al. 2018).

\section{Conclusion}

Vermicomposting of patchouli bagasse is feasible by employing Eisenia fetida. The dehydrogenase, urease and humification assay confirms the stability and maturity of the vermicomposting end products. The scanning electron microscope and x-ray diffraction analysis further substantiates the degradation, rapid mineralization of the patchouli bagasse by E. fetida and maturity of the ready vermicompost and can be used for agricultural/horticultural activities.

\section{Declarations}

\section{Acknowledgement}

The authors are grateful to the Department of Botany, Gauhati University, Guwahati for providing all the Laboratory facilities to conduct the research work.

Ethical Approval: Not Applicable

Consent to participate: Not Applicable

Consent to publish: Not applicable

Author's contributions: H.D. developed the concept of this experimental work, provided the lab facilities and guided R.A. and R.A.and H.D. wrote the main manuscript. R.A. carried out the experimental woks 
under guidance of H.D.

Funding: This research not received any funding

Competing Interests: Nothing to declare

Availability of data and materials: All the data generated during experimental works has been presented in the MS.

\section{References}

Arumugam K, Renganathan S, Babalola OO, Muthunarayanan V (2018) Investigation on paper cup waste degradation by bacterial consortium and Eudrillus eugeine through vermicomposting. Waste Manag 74:185-193. https://doi.org/10.1016/j.wasman.2017.11.009

Bhat SA, Singh J, Vig AP (2017) Instrumental characterization of organic wastes for evaluation of vermicompost maturity. J Anal Sci Technol 8:. https://doi.org/10.1186/s40543-017-0112-2

Bhat SA, Singh J, Vig AP (2015) Vermistabilization of sugar beet (Beta vulgaris $\mathrm{L}$ ) waste produced from sugar factory using earthworm Eisenia fetida: Genotoxic assessment by Allium cepa test. Environ Sci Pollut Res 22:11236-11254. https://doi.org/10.1007/s11356-015-4302-4

Bhat SA, Singh S, Singh J, et al (2018) Bioremediation and detoxification of industrial wastes by earthworms: Vermicompost as powerful crop nutrient in sustainable agriculture. Bioresour Technol 252:172-179. https://doi.org/10.1016/j.biortech.2018.01.003

Boruah T, Barman A, Kalita P, et al (2019) Vermicomposting of citronella bagasse and paper mill sludge mixture employing Eisenia fetida. Bioresour Technol 294:122147.

https://doi.org/10.1016/j.biortech.2019.122147

Boruah T, Deka $\mathrm{H}$ (2021) Biological indicators for assessing the maturity of the vermicomposted products of citronella bagasse and paper mill sludge mixture. Biomass Convers Biorefinery 1-7. https://doi.org/10.1007/s13399-020-01228-5

Cai L, Sun X, Hao D, et al (2020) Sugarcane bagasse amendment improves the quality of green waste vermicompost and the growth of Eisenia fetida. Front Environ Sci Eng 14:.

https://doi.org/10.1007/s11783-020-1240-2

Chen G, Zheng Z, Yang S, et al (2010) Experimental co-digestion of corn stalk and vermicompost to improve biogas production. Waste Manag 30:1834-1840.

https://doi.org/10.1016/j.wasman.2010.03.014

Chen W, He L, Tian S, et al (2020) Combined addition of bovine bone and cow manure: Rapid composting of Chestnut burrs and production of a high-quality chestnut seedling substrate. Agronomy 10:288. 
Das D, Deka H (2021) Vermicomposting of harvested waste biomass of potato crop employing Eisenia fetida: changes in nutrient profile and assessment of the maturity of the end products. Environ Sci Pollut Res. https://doi.org/10.1007/s11356-021-13214-z

Ganguly RK, Chakraborty SK (2019) Assessment of qualitative enrichment of organic paper mill wastes through vermicomposting: humification factor and time of maturity. Heliyon 5:e01638. https://doi.org/10.1016/j.heliyon.2019.e01638

Garcia C, Roldan A, Hernandez T (1997) Changes in microbial activity after abandonment of cultivation in a semiarid mediterranean environment. J Environ Qual 26:285-292. https://doi.org/10.2134/jeq1997.00472425002600010040x

Haritha Devi S, Vijayalakshmi K, Pavana Jyotsna K, et al (2009) Comparative assessment in enzyme activities and microbial populations during normal and vermicomposting. J Environ Biol 30:1013-1017

Hoffmann G, Teicher K (1961) A colorimetric technique for determining urease activity in soil. Dung Boden 95:55-63

Hussain N, Abbasi T, Abbasi SA (2016) Transformation of the pernicious and toxic weed parthenium into an organic fertilizer by vermicomposting. Int J Environ Stud 73:731-745.

https://doi.org/10.1080/00207233.2016.1185327

Karmegam N, Vijayan P, Prakash M, John Paul JA (2019) Vermicomposting of paper industry sludge with cowdung and green manure plants using Eisenia fetida: A viable option for cleaner and enriched vermicompost production. J Clean Prod 228:718-728. https://doi.org/10.1016/j.jclepro.2019.04.313

Lim PN, Wu TY, Clarke C, Nik Daud NN (2015a) A potential bioconversion of empty fruit bunches into organic fertilizer using Eudrilus eugeniae. Int J Environ Sci Technol 12:2533-2544. https://doi.org/10.1007/s13762-014-0648-2

Lim SL, Wu TY, Lim PN, Shak KPY (2015b) The use of vermicompost in organic farming: Overview, effects on soil and economics. J Sci Food Agric 95:1143-1156. https://doi.org/10.1002/jsfa.6849

Lim SL, Wu TY (2015) Determination of maturity in the vermicompost produced from palm oil mill effluent using spectroscopy, structural characterization and thermogravimetric analysis. Ecol Eng 84:515-519. https://doi.org/10.1016/j.ecoleng.2015.09.050

Negi R, Suthar S (2018) Degradation of paper mill wastewater sludge and cow dung by brown-rot fungi Oligoporus placenta and earthworm (Eisenia fetida) during vermicomposting. J Clean Prod 201:842-852. https://doi.org/10.1016/j.jclepro.2018.08.068 
Pandit L, Sethi D, Pattanayak SK, Nayak Y (2020) Bioconversion of ligno-cellulosic organic wastes into nutrient rich vermicompost by Eudrilus eugeniae. Bioresour Technol Reports 100580.

https://doi.org/10.1016/j.biteb.2020.100580

Patwa A, Parde D, Dohare D, et al (2020) Solid waste characterization and treatment technologies in rural areas: An Indian and international review. Environ Technol Innov 20:101066.

https://doi.org/10.1016/j.eti.2020.101066

Pellejero G, Rodriguez K, Ashchkar G, et al (2020) Onion waste recycling by vermicomposting: nutrients recovery and agronomical assessment. Int J Environ Sci Technol 17:3289-3296.

https://doi.org/10.1007/s13762-020-02685-1

Powell JT, Townsend TG, Zimmerman JB (2016) Estimates of solid waste disposal rates and reduction targets for landfill gas emissions. Nat Clim Chang 6:162-165. https://doi.org/10.1038/nclimate2804

Pramanik P, Ghosh GK, Ghosal PK, Banik P (2007) Changes in organic - C, N, P and K and enzyme activities in vermicompost of biodegradable organic wastes under liming and microbial inoculants. Bioresour Technol 98:2485-2494. https://doi.org/10.1016/j.biortech.2006.09.017

Ravindran B, Dinesh SL, Kennedy LJ, Sekaran G (2008) Vermicomposting of solid waste generated from leather industries using epigeic earthworm Eisenia foetida. Appl Biochem Biotechnol 151:480-488. https://doi.org/10.1007/s12010-008-8222-3

Romero E, Fernández-Bayo J, Díaz JMC, Nogales R (2010) Enzyme activities and diuron persistence in soil amended with vermicompost derived from spent grape marc and treated with urea. Appl Soil Ecol 44:198-204. https://doi.org/10.1016/j.apsoil.2009.12.006

Senthil Kumar D, Satheesh Kumar P, Rajendran NM, et al (2014) Evaluation of vermicompost maturity using scanning electron microscopy and paper chromatography analysis. J Agric Food Chem 62:27382741. https://doi.org/10.1021/jf4054403

Sharma K, Garg VK (2018) Comparative analysis of vermicompost quality produced from rice straw and paper waste employing earthworm Eisenia fetida (Sav.). Bioresour Technol 250:708-715. https://doi.org/10.1016/j.biortech.2017.11.101

Singh R, Singh R, Soni SK, et al (2013) Vermicompost from biodegraded distillation waste improves soil properties and essential oil yield of Pogostemon cablin (patchouli) Benth. Appl Soil Ecol 70:48-56. https://doi.org/10.1016/j.apsoil.2013.04.007

Srivastava V, Goel G, Thakur VK, et al (2020) Analysis and advanced characterization of municipal solid waste vermicompost maturity for a green environment. J Environ Manage 255:109914. https://doi.org/10.1016/j.jenvman.2019.109914 
Sudkolai ST, Nourbakhsh F (2017) Urease activity as an index for assessing the maturity of cow manure and wheat residue vermicomposts. Waste Manag 64:63-66.

https://doi.org/10.1016/j.wasman.2017.03.011

Unuofin FO, Mnkeni PNS (2014) Optimization of Eisenia fetida stocking density for the bioconversion of rock phosphate enriched cow dung-waste paper mixtures. Waste Manag 34:2000-2006.

https://doi.org/10.1016/j.wasman.2014.05.018

Usmani Z, Kumar V, Rani R, et al (2019) Changes in physico-chemical, microbiological and biochemical parameters during composting and vermicomposting of coal fly ash: a comparative study. Int $J$ Environ Sci Technol 16:4647-4664. https://doi.org/10.1007/s13762-018-1893-6

Wang P, Liu C, Chang J, et al (2019) Effect of physicochemical pretreatments plus enzymatic hydrolysis on the composition and morphologic structure of corn straw. Renew Energy 138:502-508. https://doi.org/10.1016/j.renene.2019.01.118

Wang Z, Chen Z, Niu Y, et al (2021) Ecotoxicology and Environmental Safety Feasibility of vermicomposting for spent drilling fluid from a nature-gas industry employing earthworms Eisenia fetida. Ecotoxicol Environ Saf 214:111994. https://doi.org/10.1016/j.ecoenv.2021.111994

Yadav A, Suthar S, Garg VK (2015) Dynamics of microbiological parameters, enzymatic activities and worm biomass production during vermicomposting of effluent treatment plant sludge of bakery industry. Environ Sci Pollut Res 22:14702-14709. https://doi.org/10.1007/s11356-015-4672-7

Yuvaraj A, Thangaraj R, Maheswaran R (2019) Decomposition of poultry litter through vermicomposting using earthworm Drawida sulcata and its effect on plant growth. Int J Environ Sci Technol 16:72417254. https://doi.org/10.1007/s13762-018-2083-2

Zbytniewski R, Buszewski B (2005) Characterization of natural organic matter (NOM) derived from sewage sludge compost. Part 2: Multivariate techniques in the study of compost maturation. Bioresour Technol 96:479-484. https://doi.org/10.1016/j.biortech.2004.05.019

\section{Figures}




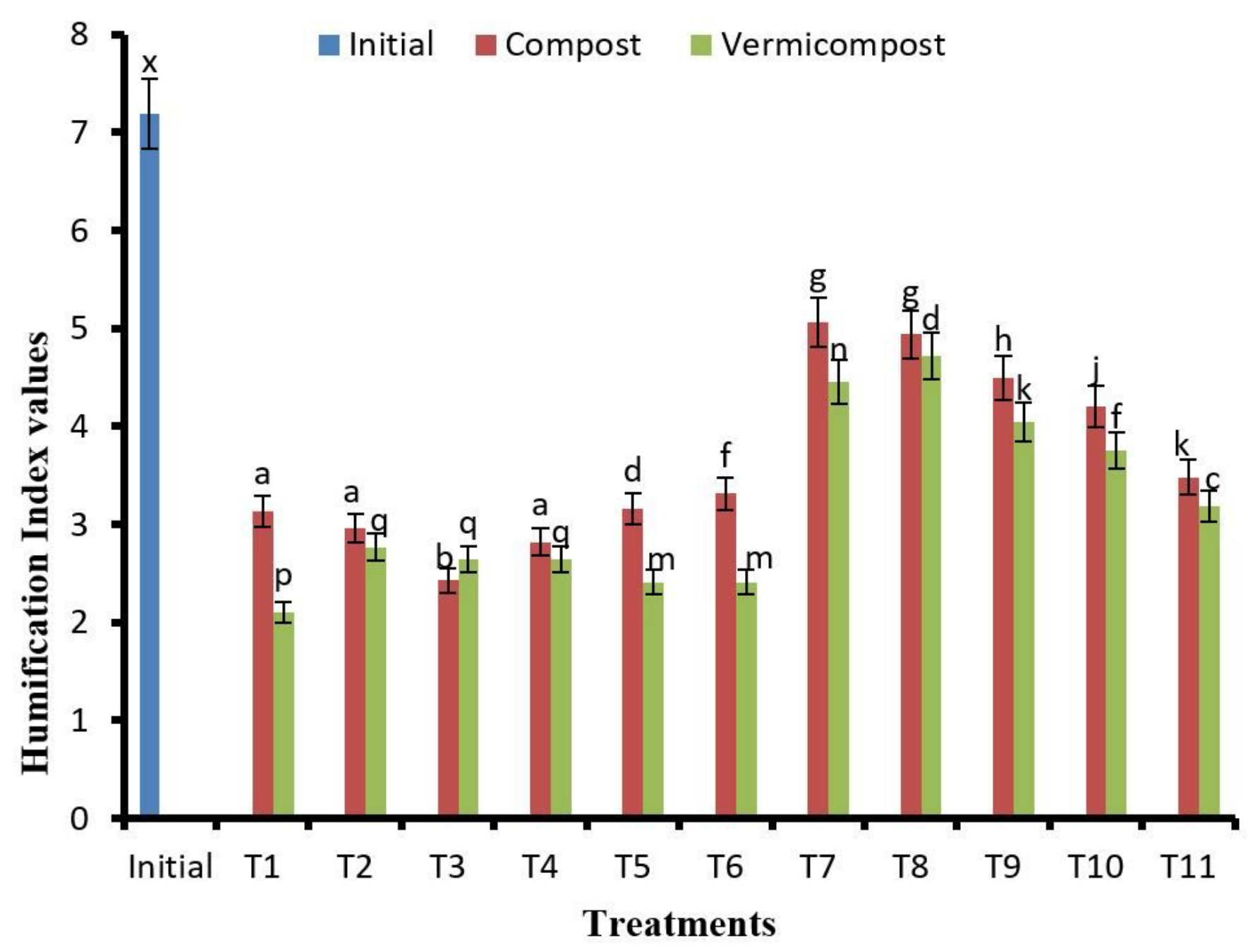

Figure 1

"Humification Index" values of initial feed mixture, compost and vermicompost samples. Mean value \pm $S D, n=3$; different letter shows statistically different values (ANOVA, LSD test, $P \llbracket 0.05$ ). 


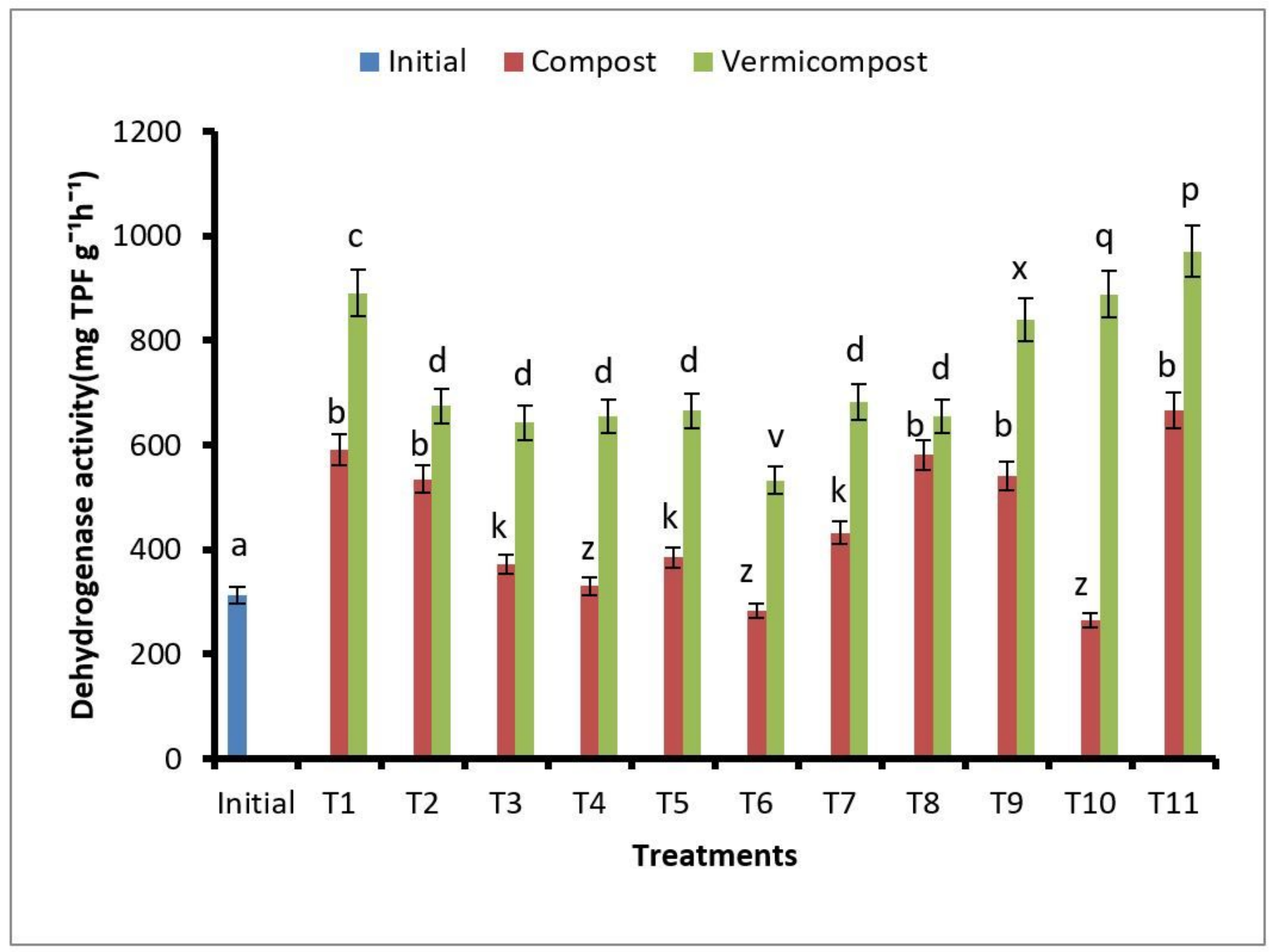

Figure 2

Dehydrogenase enzyme profiles of initial feed mixture, compost and vermicompost samples.Values are mean, $n=3$ error bars indicate SD. Different letter shows statistically different values (ANOVA, LSD test, $\mathrm{P} \otimes 0.05)$. 


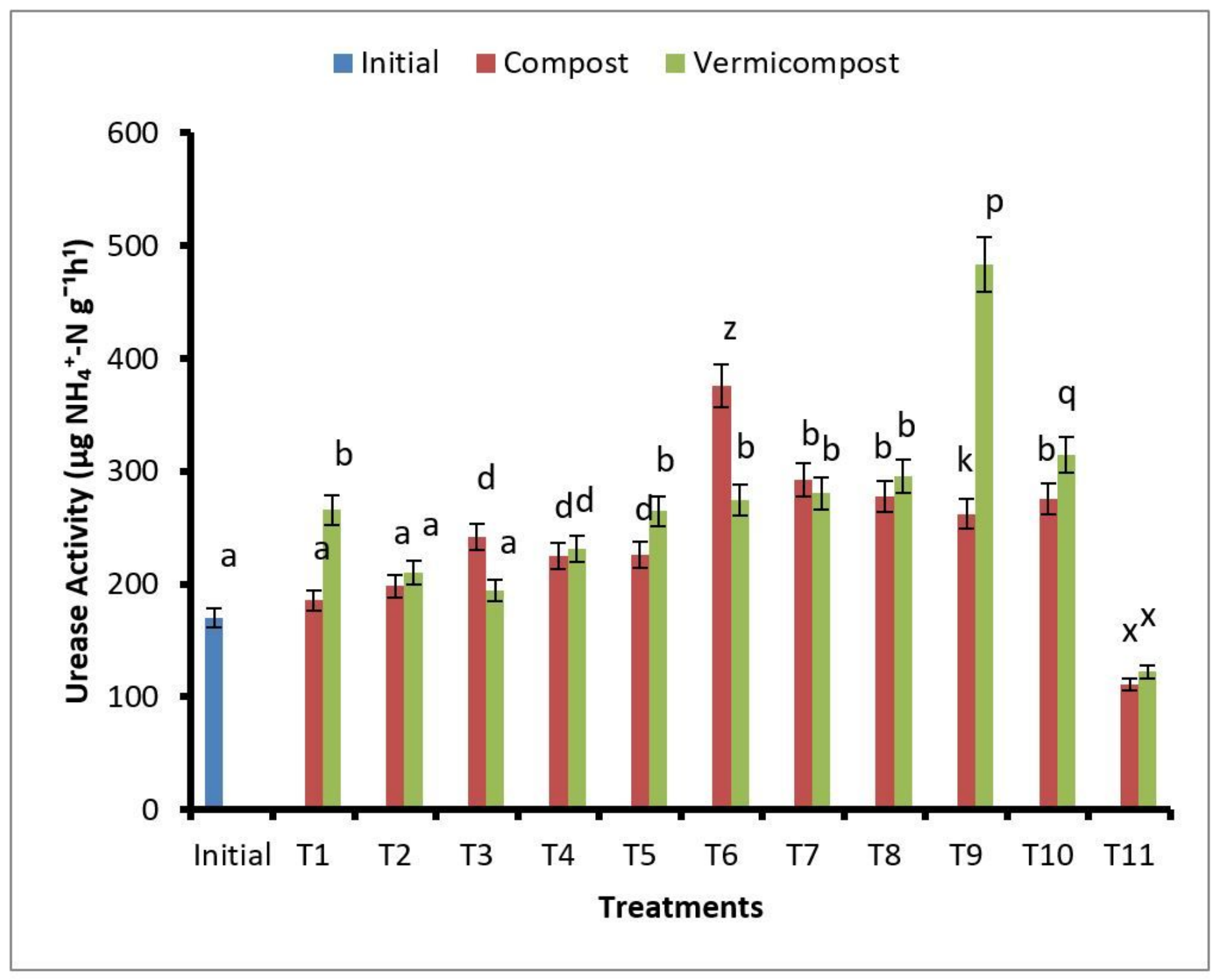

Figure 3

Urease enzyme profiles of initial feed mixture, compost and vermicompost samples. Values are mean, $n=3$ error bars indicate SD. Different letter shows statistically different values (ANOVA, LSD test, Pख0.05). 


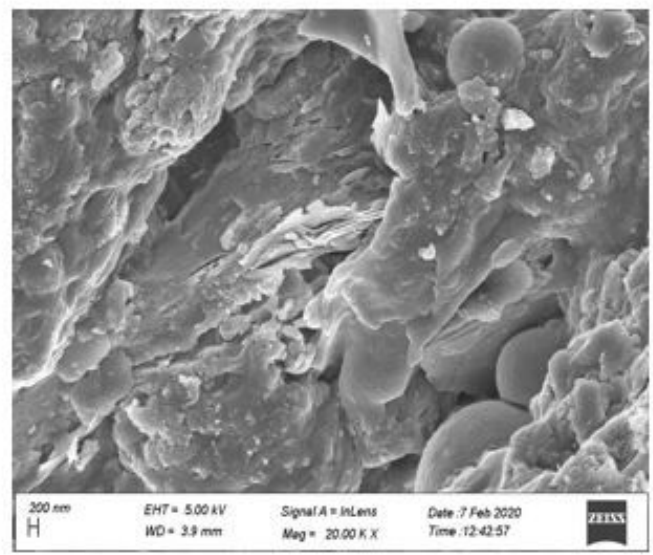

(a)

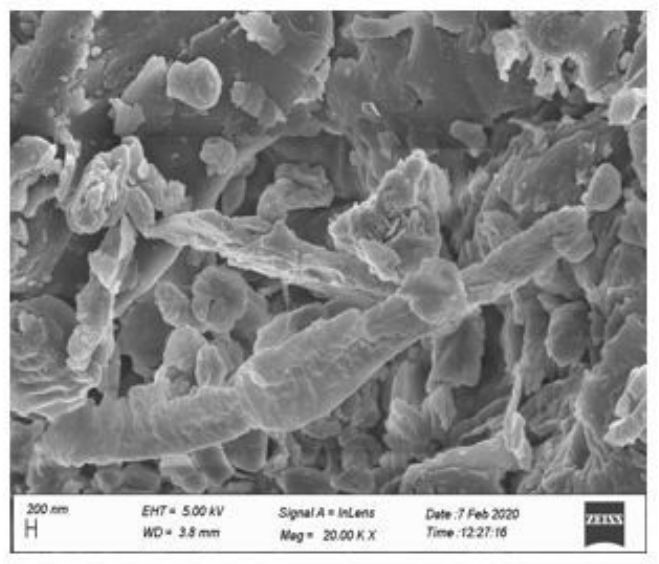

(b)

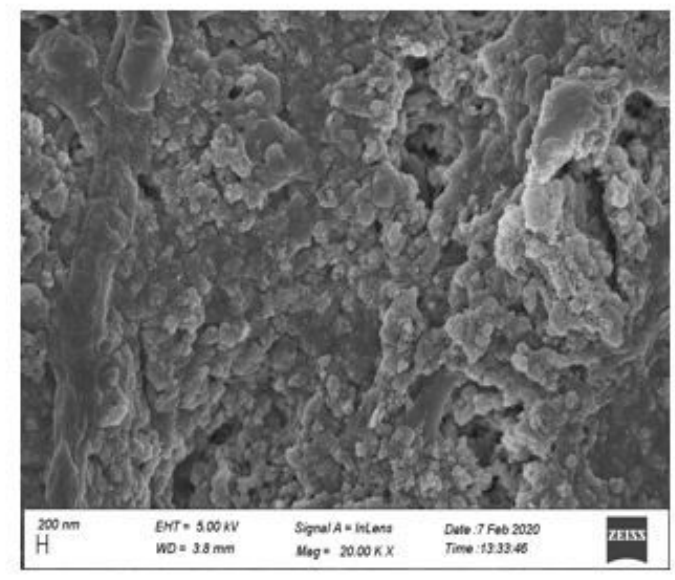

(c)

\section{Figure 4}

Showing images under scanning electron microscope (SEM) analysis images (a) Initial feed mixture (b) Compost sample (c) Vermicompost sample 


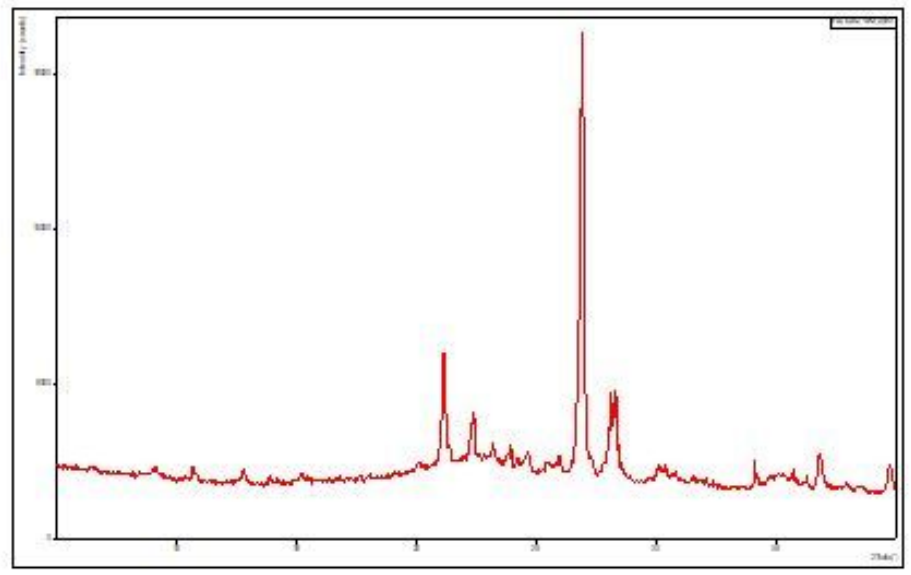

(a)

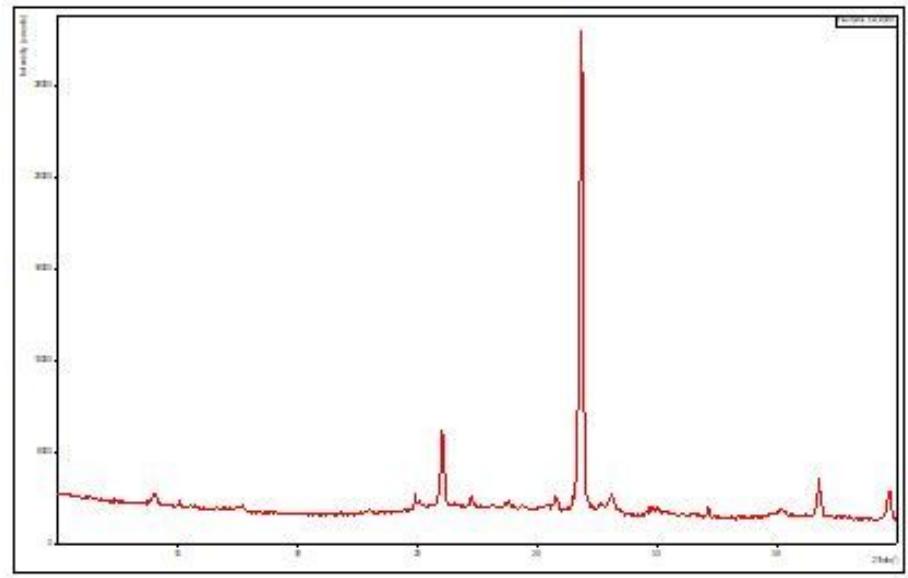

(b)

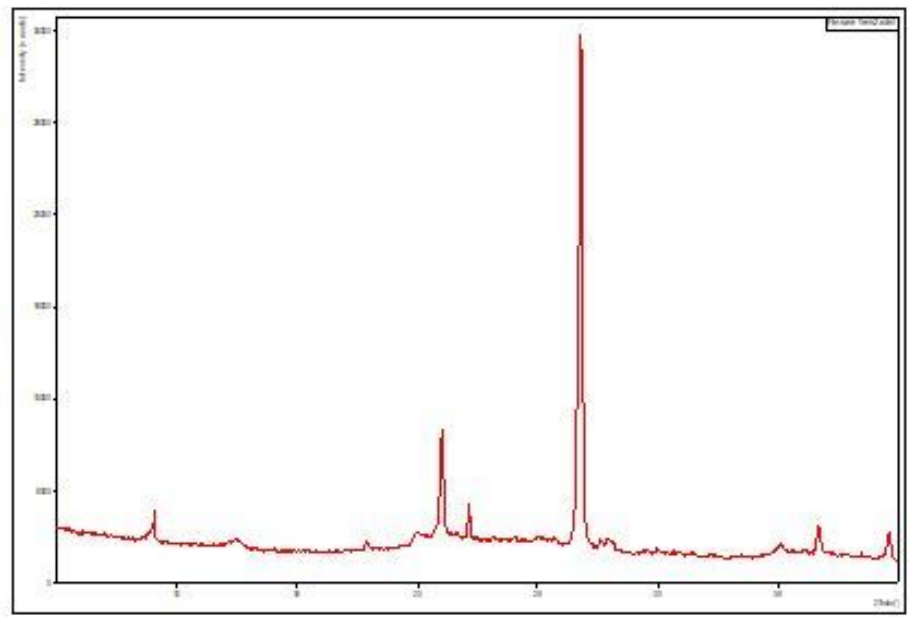

(c)

Figure 5

Showing X-ray diffraction (XRD) graph (a) Initial feed mixture (b) Compost sample (c) Vermicompost sample 